\title{
Comparison of recovery time with target controlled infusion of propofol with sevoflurane anesthesia using bispectral index monitoring in vitrectomy surgery
}

\author{
Aida Rosita Tantri, Raden Besthadi Sukmono $\triangle$, Linda Stefanie Atmadja $\triangle$ \\ Author affiliation: \\ Department of Anesthesiology and Intensive Care, Faculty of Medicine, Universitas Indonesia - Cipto Mangunkusumo National \\ General Hospital, Pangeran Diponegoro Street No. 71, Kenari, Senen, Central Jakarta, DKI Jakarta 10430, Indonesia.
}

Correspondence: Aida Rosita Tantri; E-mail: aidatantri@gmail.com; Phone: +6221-3143736

\section{Abstract}

Background: Rapid recovery after anesthesia is critical and is associated with the anesthetic agents used. The bispectral index (BIS) monitoring to guide anesthetic agents' doses may play a significant role in the recovery time. This study compared recovery time after Target Controlled Infusion (TCI) of propofol with sevoflurane anesthesia by using BIS monitoring during vitrectomy surgery.

Methodology: This was a prospective observational, randomized study on 40 patients aged 18-65y, physical status ASA I-II, body mass index (BMI) $18-30 \mathrm{~kg} / \mathrm{m}^{2}$, who underwent vitrectomy surgery. Subjects were randomly assigned into two groups, Group P - the TCI propofol group, and Group S - the sevoflurane group. Subjects in the Group P received TCI propofol (Schnider), and subjects in the Group S received sevoflurane for anesthesia maintenance, with a targeted BIS score of 40-60. Inj. fentanyl $1 \mu \mathrm{g} / \mathrm{kg}$ was administered if there was an increase in blood pressure, heart rate and/or BIS that could not be overcome by increasing the dose of TCI propofol or sevoflurane. Recovery time was calculated from when the maintenance regimen was stopped until the patient was able to obey simple commands. Recovery time, fentanyl consumption, postoperative agitation, nausea and vomiting incidence were noted and analyzed with SPSS v21.0 for Windows. T-Test or Mann-Whitney $U$ test was performed to analyze the data.

Result: Recovery time in the Group P [11.5 (5-25) min)] was not significantly different from the Group S [9 (4-18) $\min , p=0.139$ ]. Total fentanyl consumption was higher in the Group P than in the Group $S(1.765 \mathrm{vs} .1 .428 \mu \mathrm{g} / \mathrm{kg})$. The frequency of agitation during recovery was higher in the Group S than in the Group P (30\% vs. 20\%)

Conclusion: There was no significant difference in recovery time between TCl propofol and sevoflurane anesthesia using BIS monitoring in vitrectomy. Total fentanyl consumption was higher in the propofol group than in the sevoflurane group. The impact of these anesthetic regimens on postoperative agitation needs further investigation.

Key words: Intravenous anesthesia; Bispectral index monitoring; BIS; Propofol; Sevoflurane; Target Controlled Infusion; TCl; Vitrectomy

Citation: Tantri AR, Sukmono RB, Atmadja LS. Comparison of recovery time with target controlled infusion of propofol with sevoflurane anesthesia using bispectral index monitoring in vitrectomy surgery. Anaesth. pain intensive care 2021;25(6):707-712: DOI: 10.35975/apic.v25i6.1689

\section{Introduction}

Quick recovery is a much desired aspect of anesthesia. Prolonged recovery time from general anesthesia may be associated with severe complications, such as hypoxemia, hypoventilation, hypercarbia, and upper respiratory tract obstruction etc. ${ }^{1}$ Recovery time depends on the anesthetic agents used, patients' comorbidities, and the surgical factors (duration and type of the 


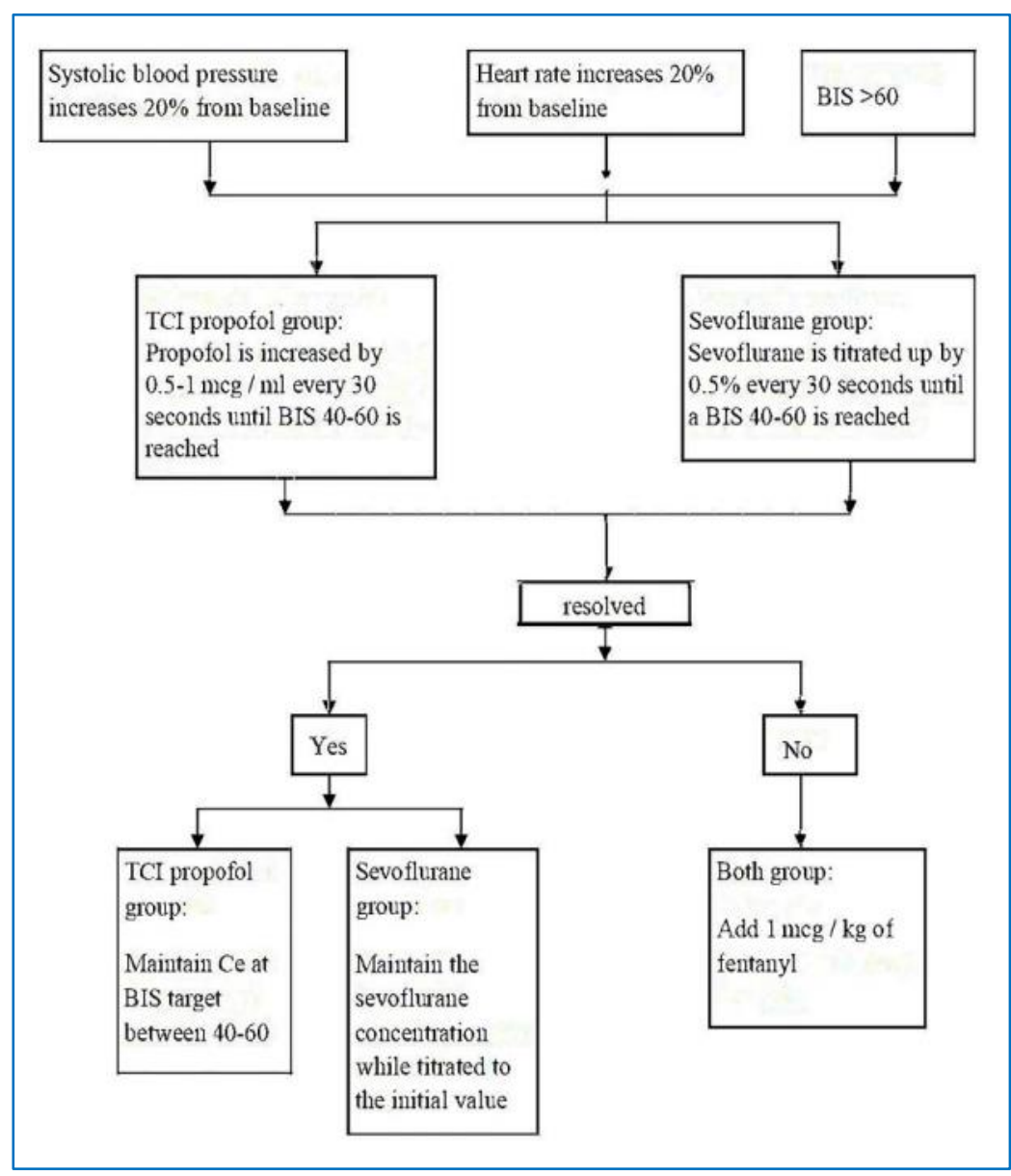

Figure 1: TCI propofol and sevoflurane dose adjustment and fentanyl addition algorithm

surgery). ${ }^{2}$ Bispectral Index (BIS) monitoring is a monitor that has been used to measure the depth of the hypnotic component of anesthesia. Adjusting the dose of anesthetics according to BIS values had been known to be associated with faster recovery. ${ }^{3}$

Vitrectomy is a relatively short procedure that aims to decrease retinal traction by cleaning blood, debris, and the vitreous humor tissue to offer better access to the retina. ${ }^{4}$ The anesthetic technique required in vitrectomy is different from other surgeries in that it should provide good hemodynamic stability and a short recovery time. ${ }^{5}$ Sevoflurane is an inhalational anesthetic agent that can be easily administered, rapidly titrated, and has a wide margin of safety. ${ }^{6}$ Propofol is an alternative short-acting intravenous anesthetics that can be given with targeted controlled infusion (TCI), which allows delivery of a precise drug concentration in a specific organ or body compartment. ${ }^{7}$ Selection of appropriate anesthetic agent, between TCI propofol and sevoflurane, with BIS monitoring in vitrectomy, can shorten recovery times and operating room turnout time.
We compared the recovery time between TCI propofol and BIS controlled sevoflurane anesthesia in vitrectomy surgery, and also the difference in postoperative agitation, nausea and vomiting, during recovery between the two treatment regimens.

\section{Methodology}

This study was a prospective observational, randomized study. The independent variables in this study were TCI propofol and sevoflurane, and dependent variables were recovery time, post operative agitation, nausea and vomiting during recovery. This research was registered in www.clinicaltrials.gov (NCT04865991). After ethical approval from the Research Ethical Committee of Faculty of Medicine, Universitas Indonesia (879/UN2.F1/ETIK/2017) and informed consent, patients aged 18$65 \mathrm{y}$, body mass index $18-30 \mathrm{~kg} / \mathrm{m} 2$, American Society of Anesthesiologists (ASA) status I-II, who were scheduled for vitrectomy surgery under general anesthesia, at Kirana's Eye Operating Theatre Cipto Mangunkusumo National General Hospital, were recruited in this study. Patients with hemodynamic instability, allergy, raised intracranial pressure, and history of malignant hyperthermia were excluded. Before surgery, patients with hearing disturbance, history of alcohol, opioids or psychotropic drug consumption, suffering from a neuropsychiatric disease, and electrolyte imbalance were also excluded from this study. Patients who experienced intraoperative cardiorespiratory disturbance, surgery lasting less than $35 \mathrm{~min}$, and patients with temperature abnormalities before being extubated from LMA would be excluded from the trial.

\subsection{Sample size}

The sample size in this trial was calculated by using an unpaired numerical analytic equation as seen below.

$\mathrm{n} 1=\mathrm{n} 2=2\left(\frac{(\mathrm{Z} \alpha+\mathrm{Z} \beta) \mathrm{S}}{\mathrm{x} 1-\mathrm{x} 2}\right)^{2}$

$\mathrm{n} 1=$ the sample size on group 1

$\mathrm{n} 2=$ the sample size on group 2

$\mathrm{Z} \alpha=$ conventional multiplier for alpha $=0.05$ (1.96)

$\mathrm{Z} \beta=$ conventional multiplier for power $=1.28$ 


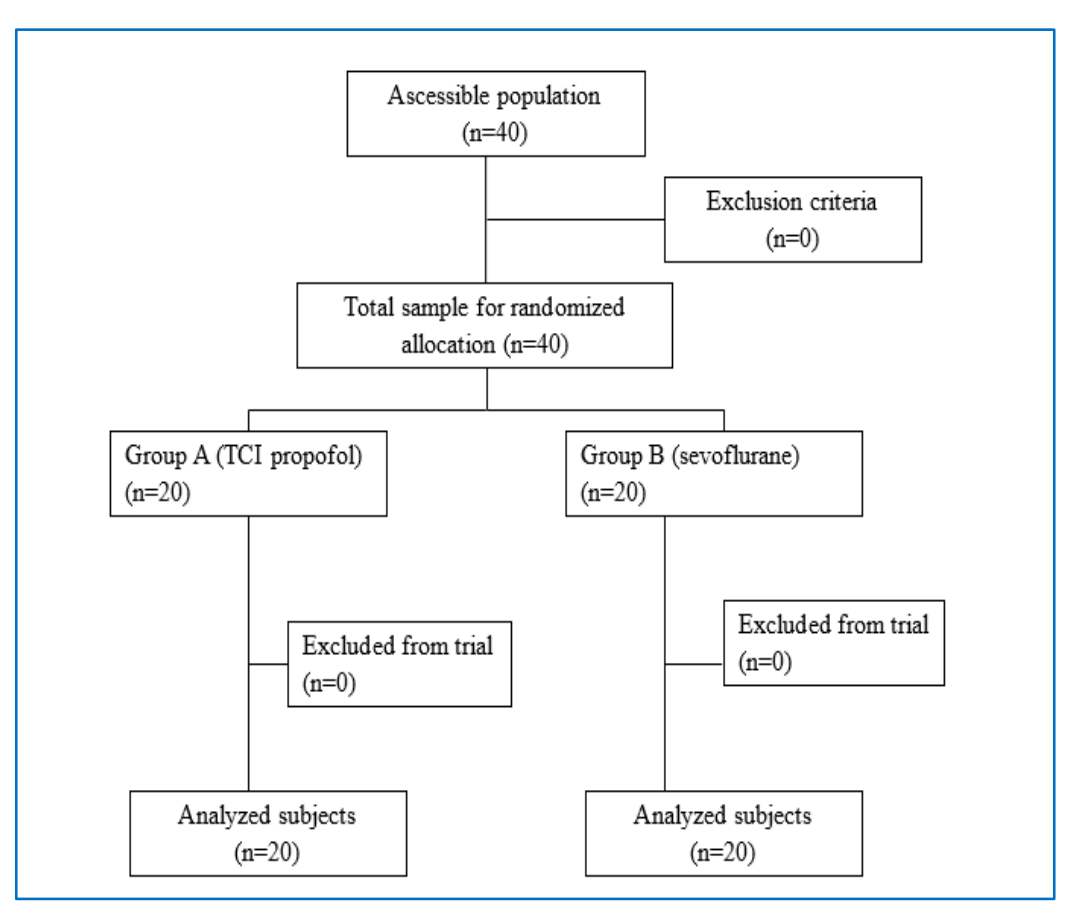

Figure 2: CONSORT study flow diagram

$\mathrm{X} 1-\mathrm{X} 2=$ the difference the investigator wishes to detect

$\mathrm{S}=$ population variance

The difference that investigators wished to detect was 2 points $(\mathrm{x} 1-\mathrm{x} 2)$, population variance $(\mathrm{S})$ was assumed 1.846 , conventional multiplier for alpha 0.05 was 1.96 and conventional multiplier for power was 1.28. Therefore, the equation worked as below:

$\mathrm{n} 1=\mathrm{n} 2=2\left(\frac{(1.96+1.28) 1.846}{2}\right)^{2}$

$\mathrm{n} 1=\mathrm{n} 2=17.88(\sim 18$ subjects $)$

The sample size that was calculated from the equations was 18 subjects. Ten percent of total subjects were added for drop-out possibility; thus, 20 subjects were recruited for each group with a total sample size of 40 subjects.

All subjects were recruited with a consecutive sampling method and randomly assigned into two groups, the Group P, and Group S. Block random allocation was done for all subjects by using the random allocator program Winpepi.

\subsection{Study Protocols}

Peripheral venous catheters were placed in all subjects. Subjects in the Group P had one specific intravenous catheter for propofol infusion apart from medication or intravenous fluid line. In comparison, subjects in the Group S were cannulated only with one venous catheter. Midazolam $0.05 \mathrm{mg} / \mathrm{kg}$ and fentanyl $1 \mu \mathrm{g} / \mathrm{kg}$ were given as premedication. Subjects in the TCI Propofol group received TCI propofol (Schneider) with targeted Ce $4-5 \mu \mathrm{g} / \mathrm{ml}$ for anesthesia induction and maintenance. Subjects in the Group $S$ received intravenous propofol $1-2 \mathrm{mg} / \mathrm{kg}$. Bispectral index (BIS) scores in both groups were titrated down to 50. Laryngeal mask airway (No. 3 or

4) was inserted three $\min$ after atracurium $\quad 0.25 \quad \mathrm{mg} / \mathrm{kg}$ was administered. All subjects were ventilated with tidal volume $8 \mathrm{ml} / \mathrm{kg}$, @ 12 times/min and $\mathrm{FiO} 2$ 50\%.

Subjects in the Group P received TCI propofol for anesthesia maintenance; $\mathrm{Ce}$ value was titrated until a targeted BIS score of 40-60 was achieved. Subjects in the Group $\mathrm{S}$ received sevoflurane 2 volume $\%$, which were titrated up/down every 5 min to get a targeted BIS score of 40-60. Blood pressure, heart rate, oxygen saturation, and BIS scores were monitored every $5 \mathrm{~min}$. Fentanyl $1 \mu \mathrm{g} /$ $\mathrm{kg}$ was added if there was an increase in blood pressure, heart rate and or BIS score that could not be overcome by increasing the dose of TCI propofol or sevoflurane. The TCI propofol and sevoflurane dose adjustment and fentanyl addition algorithm can be seen in Figure 1.

Surgery was considered complete when the palpebral retractor had been removed. After spontaneous ventilation reverted, neostigmine $0.04 \mathrm{mg} / \mathrm{kg}$ and atropine $0.04 \mathrm{mg} / \mathrm{kg}$ were given for reversal. The laryngeal mask was removed when the anesthesia was still deep enough, and subjects were monitored afterward. The time to discontinue TCI propofol and sevoflurane was recorded (T0). When the patient was fully awake and could follow simple commands, such as raising hands was recorded (Tp). Recovery time was the duration from $\mathrm{T} 0$ to $\mathrm{Tp}$. Unwanted events during recovery, such as agitation (unpleasant state of extreme arousal) and nausea-vomiting (unpleasant sensation often accompanied by the urge to vomit, and vomiting is the forceful expulsion of gastric contents through the mouth) were recorded. Total fentanyl usage during surgery was also recorded. Statistical analysis was performed using SPSS v. 21.0 software for Windows. TTest or Mann-Whitney U test were done depending on the data normality test.

\section{Results}

Forty subjects were enrolled and randomized; all completed the interventions and follow-up. Results were reported according to Consolidated Standards of 


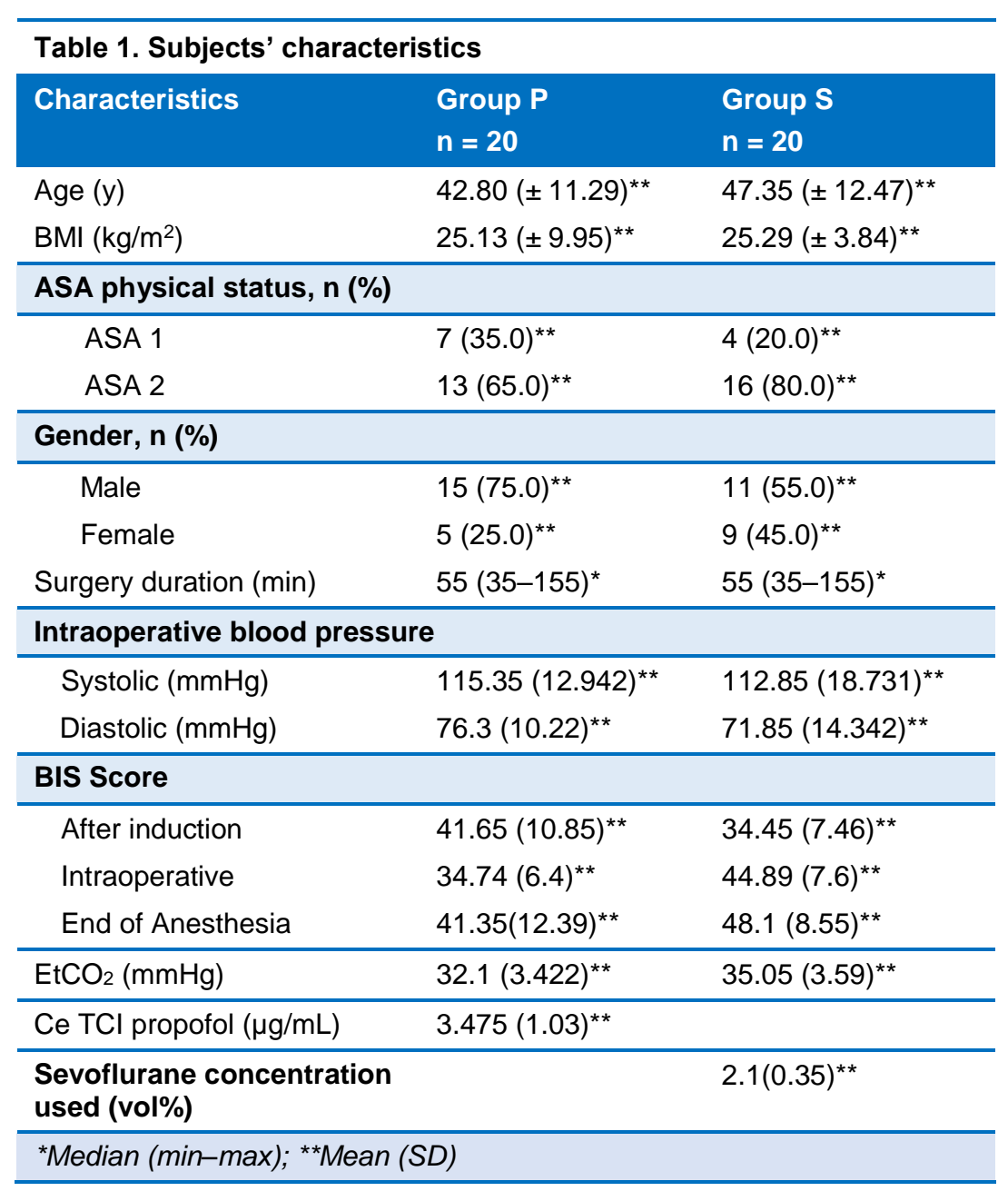

The intraoperative BIS value was lower in the Group P compared to the Group S. However, in both groups, there was no significant fluctuation in the BIS value (Figure $3 \mathrm{~A})$. Ce TCI value of propofol was high at the start of anesthesia and decreased mid-operation and increased towards the end of anesthesia. However, the Ce value towards the end of anesthesia was lower than the beginning of anesthesia (Figure 3B). The sevoflurane concentration increased intraoperatively adjusted according to the BIS value. The increase in intraoperative sevoflurane concentration did not exceed 1 vol\% (Figure 3C).

\section{Discussion}

Anesthetic agents' recovery times are closely related to their pharmacokinetics and pharmacodynamics. ${ }^{4}$ Age, gender, body mass index (BMI), and ASA physical status affect the pharmacokinetics as well as the pharmacodynamics of the anesthetic agents. In this study, age, body mass index (BMI), and ASA physical status were comparable in
Reporting Trials (CONSORT) guidelines (Figure 2). Baseline and perioperative variables were comparable between the two groups (Table 1).

During anesthesia, the Ce values of the propofol TCI group were successfully maintained below 50 . Ce value was started in high value, decreased in mid-anesthesia, and slightly increased at the end of anesthesia. The sevoflurane concentration did not increase or decrease more than 1 volume\% throughout the anesthesia. Total intraoperative fentanyl consumption in the Group $\mathrm{P}$ was higher than in the Group $\mathrm{S}$ e.g., $1.765 \mu \mathrm{g} / \mathrm{kg}$ vs. 1.428 $\mu \mathrm{g} / \mathrm{kg}$ respectively (Table 2 ).

Median recovery time in the Group P was 11.5 (5 - 25) min, while in the Group $\mathrm{S}$ was $9(4-18)$ min. There was no significant difference in recovery time between the TCI propofol and sevoflurane groups $(p=0.139)$. The incidence of postoperative agitation was higher in the Group S compared to the Group P. There was no postoperative nausea and vomitus incidence found in both groups (Table 2). both groups.

The mean age in propofol group subjects was $42.8 \mathrm{y}$, and $47.35 \mathrm{y}$ in the Group S. Geriatric patients were not included due to their higher sensitivity to anesthesia agents. In pediatric patients, who often have prolonged recovery due to hypothermia and reduced metabolism activity, were excluded from this trial. Patients with high BMI need larger doses than patients with normal BMI to get the same plasma concentration due to their extensive distribution volume. BMI subjects in both treatment arms were comparable $\left(25.59 \mathrm{~kg} / \mathrm{m}^{2}\right.$ in the Group P and 25.29 in the Group S, Table 1). ${ }^{8}$ There were more males in the Group P than in the Group S. Males have more extensive fat distribution and tend to have a longer recovery time than females. ${ }^{8}$

\subsection{Recovery time}

We titrated sevoflurane and propofol dose according to the BIS score, ensuring both arms had the same level of anesthesia. The use of BIS can ensure optimum anesthesia, which might lead to a shorter recovery time. ${ }^{9}$ BIS score is also a better predictor of patient response than patient's cardiovascular status. ${ }^{9}$ 


\begin{tabular}{|c|c|c|c|}
\hline Variable & $\begin{array}{l}\text { Group P } \\
n=20\end{array}$ & $\begin{array}{l}\text { Group } S \\
n=20\end{array}$ & $\begin{array}{l}p- \\
\text { value }\end{array}$ \\
\hline Recovery time (median, range) & $11.5(5-25)$ & $9(4-18)$ & $\begin{array}{l}0.139 \\
\mathrm{a}\end{array}$ \\
\hline Agitation, n (\%) & $16(80.0)$ & $14(70.0)$ & \\
\hline $\begin{array}{l}\text { Mean of total fentanyl dose } \\
(\mu \mathrm{g})(\text { mean } \pm S D)\end{array}$ & $113 \pm 41.49$ & $96.75 \pm 38.19$ & \\
\hline $\begin{array}{l}\text { Mean of total fentanyl used } \\
(\mu \mathrm{g} / \mathrm{kg})\end{array}$ & 1.765 & 1.428 & \\
\hline
\end{tabular}

in a study in gynecologic surgery. ${ }^{15}$ Fentanyl might extend propofol duration of action and affect the central nervous system. Further research needs to be done with a longer surgical duration and by using an ultra-short-acting opioid so that the residual effect of midazolam and fentanyl would not exist at the end of anesthesia.

Higher agitation rate was found in the Group S. There were $4(20 \%)$ incidents of agitation in the Group $\mathrm{P}$ during the recovery period and 6 $(30 \%)$ in the Group S. This finding is consistent with another study that compared agitation incidence between sevoflurane and propofol in adult patients. ${ }^{3}$ Propofol, as an anesthetic agent, was related to smooth recovery, euphoric effect, and residual sedative effect in the early stages of emergence. Propofol also has a lower incidence of postoperative nausea and vomiting and hangover, associated with a lower incidence of postoperative emergence agitation. Another theory that suggested the cause of postoperative emergence delirium is the fast recovery time of anesthetic agent, increasing the sensitivity to stimulation from the environment, triggering a functional dissociation state. ${ }^{3}$

\section{Limitations}

There were several limitations in the present study. First, the end-tidal concentration of inhalational anesthesia agents was not measured. The inhaled anesthetics endtidal concentration is the most representative measurement for the alveolar concentration. This current study provides an impetus for further research examining the effects of various anesthetic agents on recovery time in vitrectomy and other short procedures. Second, the effects of TCI and BIS focused on infusion dose adjustment rather than loading dose. Therefore, evaluation on long-term surgeries versus short-term surgeries should be conducted in the future.

\section{Conclusion}

There was no significant difference in recovery time between TCI propofol anesthesia and sevoflurane anesthesia, when monitored with bispectral index in vitrectomy. Total fentanyl consumption was higher in the TCI propofol group than in the sevoflurane group. The impact of these anesthetic regimens on postoperative agitation needs further investigation.

\section{Conflict of Interest}

The authors declare that there is no conflict of interest regarding the publication of this article. 


\section{Author Contributions}

Study concept and design: AT, RBS and LSA; analysis and interpretation of data: AT and RBS; drafting of the manuscript: LSA; critical revision of the manuscript for important intellectual content: AT, RBS and LSA; statistical analysis: LSA

\section{Funding Statement}

The authors declare that there is no funding from any party regarding the publication of this article.

\section{References}

1. Karcz M, Papadakos PJ. Respiratory complications in the postanesthesia care unit: A review of pathophysiological mechanisms. Can J Respir Ther. 2013;49:21-9. [PubMed]

2. Thomas E, Martin F, Pollard B. Delayed recovery of consciousness after general anaesthesia. BJA Educ. 2020 May;20(5):173-9. [PubMed] DOI: 10.1016/j.bjae.2020.01.007

3. Orhon ZN, Devrim S, Celik M, Dogan Y, Yildirim A, Basok EK. Comparison of recovery profiles of propofol and sevoflurane anesthesia with bispectral index monitoring in percutaneous nephrolithotomy. Korean J Anesthesiol. 2013;64(3):223-8. [PubMed] DOI: 10.4097/kjae.2013.64.3.223

4. Bock M. Anesthesiologist's Manual of Surgical Procedures, 6th ed. Anesth Analg. 2020 Sep;131(3):e144-5. DOI: 10.1213/ANE.0000000000004992

5. Deng X, Zhu T. Clinical comparison of propofol-remifentanil TCI with sevoflurane induction/maintenance anesthesia in laparoscopic cholecystectomy. Pakistan J Med Sci. 2014;30(5):1017-21. [PubMed] DOI: 10.12669/pjms.305.5196

6. Juhász $M$, Molnár $L$, Fülesdi $B$, Végh $T$, Páll $D$, Molnár $C$. Effect of sevoflurane on systemic and cerebral circulation, cerebral autoregulation and CO2 reactivity. BMC Anesthesiol. 2019 Dec 19;19(1):109. [PubMed] DOI: 10.1186/s12871-019-0784-9

7. Al-Rifai Z, Mulvey D. Principles of total intravenous anaesthesia: basic pharmacokinetics and model descriptions. BJA Educ. 2016
Mar;16(3):92-7. DOI: 10.1093/bjaceaccp/mkv021

8. Edwards $\mathrm{S}$. Anaesthetising the malnourished patient. Updat Anaesth. 2016;31. [FreeFullText]

9. Poon $\mathrm{YY}$, Chang $\mathrm{HC}$, Chiang $\mathrm{MH}$, Hung $\mathrm{KC}$, Lu HF, Wang $\mathrm{CH}$, et al. "A real-world evidence" in reduction of volatile anesthetics by BIS-guided anesthesia. Sci Rep. 2020 Jul 9;10(1):11245. [PubMed] DOI: 10.1038/s41598-020-68193-x

10. Singh S, Kumar A, Mahajan R, Katyal S, Mann S. Comparison of recovery profile for propofol and sevoflurane anesthesia in cases of open cholecystectomy. Anesth Essays. Res. 2013;7(3):386-9. [PubMed] DOI: 10.4103/0259-1162.123259

11. Liang C, Ding M, Du F, Cang J, Xue Z. Sevoflurane/propofol coadministration provides better recovery than sevoflurane in combined general/epidural anesthesia: a randomized clinical trial. $J$ Anesth. 2014 Oct 21;28(5):721-6. [PubMed] DOI: 10.1007/s00540-014-1803-0

12. Choi ES, Shin JY, Oh AY, Park HP, Hwang JW, Lim YJ, et al. Sevoflurane versus propofol for interventional neuroradiology: a comparison of the maintenance and recovery profiles at comparable depths of anesthesia. Korean J Anesthesiol. 2014;66(4):290-4. [PubMed] DOI: 10.4097/kjae.2014.66.4.290

13. Ohkushi K, Fukuda K, Koukita Y, Kaneko Y, Ichinohe T. Recovery profile and patient satisfaction after ambulatory anesthesia for dental treatment-a crossover comparison between propofol and sevoflurane. Anesth Prog. 2016;63(4):175-80. [PubMed] DOI: 10.2344/15-00012.1

14. Flood P, Shafer S. Inhaled Anesthetics. In: Flood F, Rathmell J, Shafer F, editors. Stoelting's Pharmacology and Physiology in Anesthetic Practice. 5ed. Philadelphia: Wolters Kluwer Health; 2015. p.98-160.

15. De Oliveira GS, Ahmad S, Fitzgerald PC, Marcus RJ, Altman CS, Panjwani AS, et al. Dose ranging study on the effect of preoperative dexamethasone on postoperative quality of recovery and opioid consumption after ambulatory gynaecological surgery. $\mathrm{Br} J$ Anaesth. 2011;107(3):362-71. [PubMed] DOI: 10.1093/bja/aer156 